\title{
APONTAMENTOS SOBRE UMA METODOLOGIA NIETZSCHIANA PARA O ENSINO MÉDIO
}

\section{REFERENCES ON A NIETZSCHIAN METHODOLOGY FOR HIGH SCHOOL}

\author{
Marcos de Camargo Von Zuben ${ }^{1}$ \\ Antônio Batista Soares Júnior ${ }^{2}$
}

Recebido em: 05/2018

Aprovado em: 07/2018

\begin{abstract}
Resumo: Este artigo tem como objetivo apresentar pesquisa em desenvolvimento sobre proposta metodológica de ensino de filosofia para o nível médio. Para tanto, tem como referência principal o pensamento educacional de Friedrich Nietzsche, mais especificamente dois movimentos filosóficos nietzschianos: o "tornar-se o que se é", o qual corresponde a uma necessária genealogia de si no processo de educação filosófica, e o que se liga ao tema do além-homem (über-mensch), em direção à autossuperação, à afirmação de uma singularidade criativa de si como experiência filosófica por excelência. Desse modo, procura-se discutir como esses dois movimentos podem se constituir em práticas de ensino de filosofia e como podem ser apreendidos como apontamentos para se pensar as melhores estratégias metodológicas para o ensino de filosofia. Trata-se, assim, de entender a dinâmica inerente à aprendizagem filosófica como ponto de partida para o estabelecimento de modos mais efetivos de ensinar filosofia aos estudantes do ensino médio
\end{abstract}

Palavras-chave: Nietzsche. Metodologia. Ensino médio. Prática filosófica.

\begin{abstract}
This article aims to present research in development on methodological proposal of philosophy teaching for the high school. For this, the main reference is Friedrich Nietzsche's educational thinking, specifically two Nietzschean philosophical movements: "becoming what one is," which corresponds to a necessary genealogy of oneself in the process of philosophical education, and what is linked to the theme of the beyond-man (über-mensch), towards self-improvement, to the affirmation of a creative singularity of self as philosophical experience par excellence. In this way, we try to discuss how these two movements can be constituted in practices of teaching of philosophy and how they can be apprehended as notes to think the best methodological strategies for the teaching of philosophy. It is, therefore, to understand the inherent dynamics of philosophical learning as a starting point for the establishment of more effective ways of teaching philosophy to high school students.
\end{abstract}

Keywords: Nietzsche. Methodology. High school. Philosophical practice.

\footnotetext{
${ }^{1}$ UERN - zuben@uol.com.br

${ }^{2}$ UERN - jrbatistajr@ hotmail.com
} 


\section{Introdução}

O presente trabalho visa a apresentar os resultados parciais de pesquisa em desenvolvimento que tem como objetivo a elaboração, aplicação e avaliação de proposta metodológica de ensino de filosofia no nível médio tomando como referência principal o pensamento educacional de Friedrich Nietzsche. A pesquisa procura aperfeiçoar as metodologias de ensino de filosofia no nível médio, de modo a tornar a prática filosófica mais significativa aos estudantes e mais efetiva do ponto de vista filosófico, desafio por demais presente quando, por um lado, prevalece no ensino médio a concepção técnico-científica de aprendizagem e, por outro, quando constata-se a ainda incipiente experiência da prática filosófica no ensino médio, não obstante o que já se pôde acumular de conhecimentos e troca de experiências sobre o ensino de filosofia desde o retorno da sua obrigatoriedade há dez anos no Brasil.

Os resultados apresentados se referem à apresentação e à discussão de dois movimentos filosóficos presentes em Nietzsche considerados mais importantes para pensar a educação e, em especial, o ensino de filosofia. O primeiro movimento é aquele do "tornar-se o que se é", do chegar a ser o que se é, lema de Píndaro levado ao superlativo na filosofia de Nietzsche. A esse movimento corresponde o que seria uma necessária genealogia de si no processo de educação filosófica. O segundo movimento, que se segue existencialmente ao anterior, liga-se ao tema do além-homem (über-mensch) nietzschiano, é aquele em direção à autossuperação, a afirmação de uma singularidade criativa de si como experiência filosófica por excelência. Em relação a esses dois movimentos, o que se procura responder neste estudo é: em que medida eles podem ser tomados como referência para constituição de uma prática filosófica de ensino de filosofia no nível médio?

Para a realização dos objetivos propostos, faz-se em primeiro lugar a discussão desses dois movimentos nos termos do pensamento de Nietzsche. Para tanto, toma-se como apoio os sentidos em que aparece a expressão "tornar-se o que se é" nos textos do autor e sua relação com as noções de genealogia e diagnóstico do presente. Além disso, aborda-se o tema do alémhomem em sua relação com a autossuperação criativa e com a afirmação da singularidade. Em segundo lugar, procura-se pensar como esses dois movimentos podem se constituir como práticas de ensino de filosofia, tomando-se os textos de juventude de Nietzsche (2003a, 2003b) mais relacionados com a educação como importantes referências. Por fim, argumenta-se que o ensino de filosofia precisa comportar um primeiro movimento de aprendizagem que passe por um diagnóstico da cultura específica dos estudantes, de modo a propiciar-lhes o movimento de 
um diagnóstico de si mesmos, e também criar as condições para um segundo movimento de afirmação criativa de si, momento que a singularidade própria de cada estudante pode se manifestar como aprendizagem para além de si, como superação de si.

O que é de interesse nesta investigação não é tanto a discussão sobre todos os aspectos implicados aos problemas da educação, formação, ensino, aprendizagem presentes no pensamento do filósofo alemão, mas antes a apreensão do que se nomeia os movimentos da prática filosófica que possam constituir-se como apontamentos para se pensar as melhores estratégias metodológicas para o ensino de filosofia. Trata-se, assim, de compreender a dinâmica inerente à aprendizagem filosófica como ponto de ancoragem para o estabelecimento de modos mais efetivos de ensinar filosofia aos estudantes do ensino médio.

\section{Diagnóstico do presente para "tornar-se o que se é" no processo de educação filosófica}

O “tornar-se o que se é”, como primeiro movimento, perpassa o caráter sempre genealógico da investigação filosófica. Em A Gaia Ciência no aforismo 270 Nietzsche (2001, p. 186) afirma: "O que diz sua consciência? - 'Torne-se aquilo que você é”. É válido ressaltar que essa frase é, antes de tudo, lema de Píndaro, porém ganha uma espécie de ressignificação na filosofia de Nietzsche quando este atribui à referida frase uma interpretação que a eleva a um sentido propriamente criativo, o que possibilita pensar o aspecto da formação.

Segundo Foucault (1994, p. 606), a partir de Nietzsche a filosofia tem por tarefa “diagnosticar, realizar um diagnóstico do presente, dizer o que somos hoje e o que significa hoje dizer isto que nós somos". Este trabalho de realizar o diagnóstico da atualidade passa, necessariamente, para Nietzsche (1998, p. 60), pela realização de um trabalho genealógico em relação aos conceitos, valores e modos de vida.

É a partir desse diagnóstico, dessa genealogia de si, que se começa a articular o primeiro movimento - tornar-se o que se é - como impulso do vir a ser, que se põe como ponto de partida para a formação filosófica. Esse movimento está intimamente relacionado com a bildung, que "poderia ser entendida como a ideia que subjaz ao relato do processo temporal pelo qual um indivíduo singular alcança sua própria forma, constitui sua própria identidade, configura sua particular humanidade ou, definitivamente, converte-se no que é” (LARROSA, 2009, p. 45). Esse processo que intervém a um diagnóstico de si, perpassa também por um diagnóstico da cultura já que "Nietzsche, também se insere, vigorosamente, na crítica da cultura e das instituições de cultura de seu tempo" (LARROSA, 2009, p. 44). Nessa perspectiva, esse 
movimento, com vistas a um caráter formativo na educação filosófica, é um convite nietzschiano ao sujeito para o experimento de si próprio na esfera do "formar a si próprio", do "fazer-se a si próprio", “cultivar a si próprio".

Nesse processo, o sujeito é este que percebe "o que se é" no presente, tendo em vista um "tornar-se". Em outras palavras, no processo formativo, o sujeito reconhece sua real condição - o que se é - faz um diagnóstico de si no presente, momento reflexivo sobre si, sobre o que se é hoje, se autocompreende, e, a partir disso, movimenta-se ao "tornar-se" (transformarse), momento em que sua singularidade atinge sua própria forma, cria, traz à tona sua própria identidade, e transforma-se no que se é. Com isso, segundo Larrosa (2009, p. 46):

[...] o processo de "chegar a ser o que se é" do protagonista aparece como dobrado sobre si mesmo e, contado em dois planos ao mesmo tempo, o plano sucessivo dos acontecimentos e o plano reflexivo, construído a partir do final, em que cada um dos momentos temporais é mostrado a partir de seu resultado.

A autocompreensão reflexiva de si como resultado, como diagnóstico de si traz à tona o que se é, e o "tornar-se" é o que faz, o que move, o que transforma o sujeito, o que o impulsiona a tornar-se cada vez mais. De modo que [...] "Só quando uma vontade puramente afirmativa atravessa 'o que se é', o homem se converte em 'o que é'” (LARROSA, 2009, p. 61). Esse movimento no processo de educação filosófica é o que impulsiona a formação da singularidade do sujeito na medida em que este torna-se, assim, criador de sua própria forma.

Dessa maneira, o convite nietzschiano ao sujeito para tornar-se o que se é traz consigo o caráter de ser um sujeito diferente, não pertencente à massa. Na III Consideração Intempestiva: Schopenhauer Educador o filósofo alemão destaca o caráter de libertação do sujeito no seu trajeto educacional no que se refere a este não querer pertencer à massa, e isso se expressa quando o mesmo afirma:

O homem que não quer pertencer à massa só precisa deixar de ser indulgente para consigo mesmo; que ele siga a sua consciência que lhe grita: "Sê tu mesmo! Tu não és isto que agora fazes, pensas e desejas". Toda alma jovem ouve este apelo dia e noite, e estremece; pois ela pressente a medida de felicidade que lhe é destinada de toda a eternidade, quando pensa na sua verdadeira emancipação: felicidade à qual de nenhum modo alcançará de maneira duradoura, enquanto permanecer nas cadeias da opinião corrente e do medo. E como pode ser desesperada e desprovida de sentido a vida sem esta libertação! (NIETZSCHE, 2003a, p. 139). 
Ora, este sujeito obedece à sua consciência e diz para si que não pode se acomodar com sua condição, propondo-se a si mesmo um tornar-se, ser ele mesmo, buscando assim, ser diferente e não pertencer à massa. Neste sentido, nosso filósofo se engaja em seu projeto de elevação da cultura, mas de uma cultura superior, uma cultura de indivíduos selecionados, pois: "[...] não é a cultura da massa que deve ser a nossa finalidade, mas a cultura de indivíduos selecionados, munidos das armas necessárias para a realização das grandes obras que ficarão" (NIETZSCHE, 2003b, p. 90). Contudo, Nietzsche pressupõe que se já é sempre uma consciência gregária e massificada enquanto ser social e cultural, e que assim se deve, por um movimento genealógico em relação aos próprios valores, por uma genealogia de si, tomar distância daquilo que nos torna a todos comuns e iguais, da consciência comum e pacificada da coletividade, para deixar emergir aquilo que em cada um é singular e próprio. Segundo Larrosa (2009, p. 50), "Nietzsche propõe uma série de exames de consciência que inclui um olhar reflexivo até os próprios educadores, e que servirá como transição pra um deslocamento do olhar até Schopenhauer, até a filosofia como forma de vida, ou se se quer, como disciplina da indisciplina”. Esse exame de consciência que o sujeito faz de si e desvia o olhar direcionandoo aos educadores é um movimento de voltar a atenção para o modelo de formação que está posto. Esse é um impulso que deve ser colocado em movimento.

[...] E esse impulso vem geralmente de um viajante, de um Wanderer, cuja única função é despertar no jovem a nostalgia do longínquo, a nítida sensação de que a vida está em outra parte. O viajante vem de longe para interromper a comodidade do habitual e do acostumado, para produzir a diferença entre o que se é e o que vem a ser [...] (LARROSA, 2009, p. 51).

Se tomarmos a figura do Wanderer, do viajante, como a figura do professor de filosofia, pode-se dizer que uma de nossas tarefas é quebrar essa comodidade do habitual, daquilo que é de costume-cômodo do nosso aluno, e assim, impulsioná-lo a perceber-se tal como é e direcioná-lo ao vir a ser, levando em consideração o horizonte da educação filosófica na perspectiva nietzschiana, conforme esclarece Larrosa $(2009$, p. 51), [...] “O viajante desfaz o que se é, separa o jovem protagonista de seu mundo e de si mesmo, e o lança a um vir a ser, aberto e indefinido".

Desse modo, pode-se tomar o "tornar-se o que se é" como forma de vida, uma vez que em A Gaia Ciência, especificamente no final do parágrafo 299, intitulado "O que devemos aprender com os artistas", Nietzsche (2001, p. 202) explica: [...] "Pois neles esta sutil capacidade termina, normalmente, onde termina a arte e começa a vida; nós, no entanto, 
queremos ser os poetas-autores de nossas vidas, principiando pelas coisas mínimas e cotidianas". Sobretudo, o convite nietzschiano ao sujeito para tornar-se o que se é, propõe a este ser autor de si, criador de si e da própria vida tendo em vista um reconhecimento de si em direção a um pleno e constante tornar-se, pois o sujeito é este que somente ele é quem pode construir-se no fluxo da vida, e claramente Nietzsche afirma (2003a, p. 140 - 141):

\begin{abstract}
Ninguém pode construir no teu lugar a ponte que te seria preciso tu mesmo transpor no fluxo da vida - ninguém, exceto tu. Certamente, existem as veredas e as pontes e os semideuses inumeráveis que se oferecerão para te levar para o outro lado do rio, mas somente na medida em que te vendesses inteiramente: tu te colocarias como penhor e te perderias. Há no mundo um único caminho sobre o qual ninguém, exceto tu, poderia trilhar. Para onde leva ele? Não perguntes nada, deves seguir este caminho.
\end{abstract}

Percebe-se que no processo do "torna-se o que se é" o sujeito precisa encontrar o seu próprio caminho. É caminho único que somente o sujeito - ele mesmo - pode se direcionar a um tornar-se. E nessa perspectiva nietzschiana a invenção tem um papel crucial para o tornarse do sujeito, pois como diz Larrosa (2009, p. 45): [...] "isso que somos e que temos de chegar a ser está claramente do lado a invenção. O homem é um animal de invenção, e as diferentes formas de consciência não são senão produtos dessa função inventiva, dessa capacidade de invenção".

Com efeito, nesse processo em que a educação filosófica se faz importante no pensamento nietzschiano, há um aspecto que possibilita pensar sobre um apontamento para uma metodologia. Segundo Larrosa (2009, p. 45), [...] "Há uma passagem no Ecce Homo em que Nietzsche constrói a imagem do leitor perfeito como 'um monstro de valor e curiosidade, e, além disso, uma coisa dúctil, astuta, precavida, um aventureiro e um descobridor nato"” (NIETZSCHE, 1971, p. 60 apud LARROSA, 2009, p. 45). Ora, com esse trecho, pode-se dizer que no processo de ensino de filosofia, na educação filosófica, há a necessidade de que haja leitura, a qual torna-se um meio imprescindível para a educação filosófica. Daí, então, a importância de tomá-la como um apontamento fundamental para constituição de conhecimento e de meio para o ensino de filosofia.

O caráter singular do sujeito como invenção de si na filosofia de Nietzsche se identifica com o processo de educação filosófica que traz consigo a ideia de criação de um mestre da leitura, que incita, que estimula à leitura, pois segundo Larrosa (2009, p. 38-39):

A escrita de Nietzsche cria um mestre da leitura ou, o que é mesmo, um mestre de dança, um incitador à aventura, um educador do homem por vir a ser. [...] 
Ensina, portanto, o silêncio da leitura, a atenção e a humildade da leitura, a delicadeza e a lentidão da leitura. O mestre da leitura é o iniciador aos segredos daquela atividade.

Pode-se relacionar esse movimento da leitura com a figura do professor de filosofia que procura impulsionar e estimular seus alunos à prática da leitura, já que, como diz o referido autor (LARROSA, 2009, p. 39), "Se ler é como viajar, e se o processo de formação pode ser tomado também como uma viagem na qual cada um venha a ser o que se é, o mestre da leitura é um estimulador para a viagem. Mas uma viagem tortuosa e arriscada, sempre singular, que cada um deve traçar e percorrer por si mesmo". Assim, a leitura na aula de filosofia torna-se importante, pois ela faz parte da construção filosófica do estudante no Ensino Médio no que se refere a este "tornar-se o que se é" na expectativa constante de construir-se a si mesmo.

O sentido do tornar-se o que se é se delineia na filosofia nietzschiana sob a perspectiva do sujeito que se cria, de um "eu inventor artista de si que se inventa", ou seja:

[...] O eu que importa é aquele que há sempre além daquele que se toma habitualmente por sujeito: não está por descobrir, mas por inventar; não por realizar, mas por conquistar; não por explorar, mas por criar da mesma maneira que um artista cria uma obra. Para chegar ao que se é, tem que se ser artista de si mesmo. (LARROSA, 2009, p. 64-65)

Ser artista de si mesmo é a proposta nietzschiana que vai ao encontro da singularidade do sujeito que concebe a ideia criativa de si em um pleno inventar, em um pleno "tornar-se". Contudo, para Larrosa $(2009$, p. 39), “[...] Chegar a ser o que és! Talvez a arte da educação não seja outra senão a arte de fazer com que cada um torne-se em si mesmo, até sua própria altura, até o melhor de suas possibilidades. Algo, naturalmente, que não se pode fazer de modo técnico nem de modo massificado". Assim, entende-se que o lema "tornar-se o que se é" representa um movimento que perpassa a singularidade do sujeito e que por isso está intimamente ligado ao processo de aprendizagem filosófica como um movimento necessário à prática filosófica.

Baseando-se nisso, reflete-se a seguir a respeito da filosofia como invenção de si, partindo da análise da definição de vida para o filósofo alemão.

\section{Filosofia como invenção de si: a definição de vida como vontade de potência e a vontade criadora para a construção do além do homem}


Pensemos então como Nietzsche propõe a definição de "vida" como "vontade de potência" e o termo "vontade criadora" na perspectiva da criação de si, partindo da análise do campo da moral, para pensarmos tais conceitos na esfera da elevação do homem, e, ainda, pensarmos como podem se tornar necessários no processo educacional filosófico na vida dos educandos, trazendo para discussão as ideias de "autossuperação" e "além do homem".

Diante disso, surge uma curiosa questão: o que é vida para Nietzsche? No livro intitulado Nietzsche, vida como obra de arte, Maria Rosa Dias, ao interpretar as ideias do filósofo, revela o que para ele significa ser vida assim como também demonstra as indagações dele acerca das leis morais quando escreve:

[...] Para Nietzsche, pensar, sentir, avaliar são sempre sintomas das formas de vida, de sua plenitude, de sua potencialidade ou de suas obstruções, seus cansaços e empobrecimentos. Em um fragmento póstumo, ele faz algumas perguntas: "Que valem nossas apreciações valorativas e nossas próprias tábuas de leis morais? O que resulta de sua dominação? Para quem? Em relação a quê? - Resposta: para a vida. Mas o que é vida? Aqui se faz, portanto, necessária, uma nova concepção mais precisa do conceito de 'vida': minha fórmula sobre isso se enuncia: a vida é vontade de potência". (DIAS, 2011, p. $33)$.

Assim, pensar, sentir e avaliar estão inclusos no caráter próprio da vida, são sintomas das formas de vida. Em suas indagações acerca da moral, o filósofo faz referência ao fato de tais leis morais resultarem em dominação à vida, ou seja, essas leis que damos a nós próprios não nos permitem viver intensamente, não nos permitem expandir nossa potencialidade. Com efeito, ao nos dizer que as leis morais resultam em dominação, Nietzsche procura, a nosso ver, dizer também o que pensa ser "vida" em contraposição àquilo que é posto como dominação à vida. Sobretudo, o conceito de vontade de potência é de grande importância na filosofia nietzschiana, e para ele vontade de potência é vida. Entretanto, se para Nietzsche a vida é "vontade de potência", o que isso significa? Segundo Dias (2011, p. 34),

[...] é na seção intitulada 'Da superação de si' que o filósofo equipara o conceito de vontade de potência ao de vida. Nesse momento, caracteriza a vontade de potência como vontade orgânica; ela é própria não unicamente do homem, mas de todo ser vivo. [...] A vida, como vontade de potência, como eterno superar-se, é, antes de tudo, atividade criadora e como tal é alguma coisa que quer expandir sua força, crescer, gerar mais vida.

Desse modo, o filósofo conceitua vida como vontade de potência na medida em que é "atividade criadora"; é atividade criadora na medida em que quer gerar mais vida, um eterno 
superar-se. Vontade de potência está estritamente ligada à vontade que, por assim dizer, quer estar em constante crescimento, querendo de fato expandir sua força. A vontade de potência é também caracterizada como vontade orgânica, porém, esta existe em todos os seres vivos e não apenas no homem. A esse respeito Dias (2011, p. 43) explica que, "Segundo Nietzsche, a vontade de potência é 'o mais forte de todos os impulsos, aquele que até hoje dirige toda evolução orgânica'. Os instintos, os impulsos, a atividade, a força são, em última instância, a linguagem particular da vontade de potência" [...]. Vontade de potência é o que impulsiona o movimento da vida, é atividade criadora, um eterno superar-se.

Para dar continuidade à discussão sobre vontade de potência como vida e para se entender o caráter desse termo como atividade criadora, faz-se necessário compreender que Nietzsche, além de ser um defensor da vida, é também um defensor da arte. Para ele, a arte é elemento que conduz à atividade criadora, que coloca o homem em um patamar de construir-se a si mesmo, e é a partir dessa perspectiva da arte que o filósofo deseja fazer uma conexão, uma interligação entre vida, pensamento e arte.

Mas o que o filósofo compreende por arte e o que ela tem a ver com a existência em seu sentido mais amplo em relação à vida? Com base na interpretação dos escritos nietzschianos, Dias (2011, p. 56) explica:

[...] A arte é essencialmente afirmação, divinização da existência. Nietzsche valoriza os impulsos estéticos como condição de criação de novas condições de existência. Depois que a tradição europeia negou a vida em nome de valores ditos superiores, só resta proclamar a "potência criadora" como padrão de uma vida sã e forte: 'A arte e nada mais do que a arte! Ela é a grande possibilitadora de vida, a grande aliciadora da vida, o grande estimulante da vida'.

A arte está estritamente ligada à existência, pois a partir da arte e dos impulsos estéticos pode haver, para Nietzsche, criação de novas condições de existência, em outras palavras, novas formas de vida. Se em prol de outro mundo a tradição filosófica negou a vida em nome de valores superiores depositando uma crença na razão com base na metafísica, agora precisamos não mais negar a vida como fez a tradição, e sim afirmá-la. É com a "potência criadora" que se pode trazer isso à tona. A potência criadora e a arte são o que estimulam à vida, que a tornam possível. Desse modo, é por meio da arte que se pode afirmar a vida, dar propriamente sentido à existência.

Posto que arte é essencialmente afirmação, faz-se necessário compreender o termo "vontade de potência" como "atividade criadora". Os dois termos estão interligados ao conceito de "vida como vontade criadora". A vontade de potência como algo que quer crescer, gerar 
mais vida, é, portanto, vontade criadora. Para Nietzsche, a vontade criadora está estritamente relacionada com a arte e a vida. Uma vez que a arte é o grande estimulante da vida, a vontade criadora é a força que impulsiona o ato de criar. Criar é, para o filósofo, a atividade que produz constantemente a vida: [...] "criar é uma atividade constante e ininterrupta. É estar sempre efetivando novas possibilidades de vida" [...] (DIAS, 2011, p. 65).

Criar é algo próprio da vida na medida em que possibilita novas formas de vida. Estas se efetivam quando a vontade criadora impulsiona o ato de criar fazendo com possam estar em constante vir-a-ser, podendo, pois, gerar vontade de crescer cada vez mais. Com efeito, para o filósofo, criar "é vontade de vir-a-ser, crescer, dar forma, isto é, criar e, no criar, está incluído o destruir" (NIETZSCHE apud DIAS, 2011, p. 65). O destruir é, para o filósofo alemão, algo próprio do devir, da mudança. Entretanto, sobre a vontade criadora como algo que se relaciona com o devir, Dias (2011, p. 70) diz:

A doutrina da vontade criadora, a vontade como força artística, tal como Nietzsche a concebe, é uma nova maneira de pensar que se aplica ao devir. Não há começo, nem ponto final; tudo está ainda por se fazer. E dizer que tudo está em mudança é dizer que tudo está sujeito às leis da destruição. A realidade do devir, da mudança, é a única realidade.

A possibilidade do criar como sendo algo próprio da vida se justifica justamente porque tudo está em plena mudança como também está para se fazer, uma vez que não há começo nem fim, e, desse modo, tudo está sujeito às leis da destruição. Logo, no criar também está incluso o destruir, mas este como possibilidade do vir-a-ser, e sendo assim, o devir é, por assim dizer, condição para que haja constante criação. Portanto, é nessa perspectiva que vontade de vir-aser, de crescer, significa atividade que produz constantemente a vida. Assim, vontade como força artística, na perspectiva nietzschiana, é vontade criadora na medida em que é atividade criadora. Sobretudo, a arte é o que estimula, é o estimulante que impulsiona a vida como vontade criadora.

Ora, o movimento do "tornar-se o que se é" e o movimento de "vontade de potência" como "vontade criadora" se configuram no âmbito da "autossuperação de si" na medida em que estão imersos na esfera da afirmação de uma singularidade criativa de si como experiência filosófica por excelência. O que se afirma nesse movimento positivo é a potência criativa de autossuperação, a afirmação do vir a ser próprio de cada um. O devir na perspectiva de um vira-ser, no sentido do criar a si mesmo, traz consigo a proposta de fazer com que as singularidades (os educandos) possam experienciar-se, criar-se, construir-se, e assim, desenvolver suas 
potencialidades tendo em vista um superar-se, refletindo sobre sua vida como vontade criadora de si. Nesse ponto, a noção de além-homem e a ideia de autossuperação nietzschiana constituem-se como ancoragem necessária para pensar a aprendizagem filosófica, que estruturam esse segundo movimento inerente às práticas filosóficas.

Os movimentos aqui discutidos são um convite nietzschiano aos educandos a conceber suas singularidades como potência criadora de si mesmo em direção a uma autossuperação de si mesmo. É um convite para que a experiência filosófica de si ultrapasse sua condição massificada em direção a novas formas de ser e de pensar.

\section{Metodologia das aulas de filosofia: um esboço}

Nesta seção, realiza-se um primeiro esboço de proposta metodológica para as aulas de filosofia do nível médio, em que estão presentes os dois movimentos considerados inerentes à prática filosófica: a genealogia de si e a autossuperação. Importante frisar que não se trata de apresentar uma proposta acabada e formalmente organizada em uma metodologia de ensino, mas antes indicar a direção que esses dois movimentos metodológicos podem assumir quando considerada sua aplicação em uma metodologia de ensino.

O primeiro movimento genealógico, como se viu, tem implicada a tarefa de articular as condições didáticas para a realização da crítica da cultura em articulação com as teorias, conceitos e ideias filosóficas que de algum modo a sustentam ou dão sentido às práticas culturais vigentes dos estudantes.

Assim, um primeiro passo essencial é, partindo do conteúdo a ser ensinado, por exemplo, o tema da democracia, realizar um levantamento dos valores, compreensões e ideias que os estudantes têm sobre essa temática, de preferência, fazendo o registro individual da atividade, para que se possa utilizar essas anotações em outra etapa da metodologia, como registro de um ponto de partida. Aqui pode intervir a utilização de dimensões da cultura que estejam diretamente relacionadas com o tema da democracia, provindas de variados meios e feitos em registros linguísticos e imagéticos diversos, como o texto de uma lei, a imagem de uma assembleia, uma teoria científica, uma canção musical, um artigo de opinião sobre direitos e deveres em uma democracia, uma poesia, um conto ou um filme, entre outros. O importante nesse primeiro passo não é somente apresentar e discutir aspectos de nossa cultura, mas diferentemente, buscar identificar os valores culturais e também os conceitos e as ideias 
filosóficas subjacentes a essas práticas estudadas visando a perceber de que modo esses valores e essas ideias estão presentes e são incorporados pelos próprios estudantes e pelo professor.

O segundo passo, que finaliza o movimento genealógico, volta-se para o conhecimento filosófico das teorias e dos conceitos implicados com a temática abordada. A escolha das teorias, dos conceitos e dos respectivos autores não deve ser aleatória. Como se trata de uma genealogia da cultura, no caso a nossa, ocidental e brasileira, as teorias a serem priorizadas no estudo são aquelas que pretendem fundamentar, no caso do exemplo utilizado, as práticas políticas que configuram o modelo democrático republicano ocidental. Assim, como se trata de pensar o chamado Estado democrático de direito, os fundamentos liberal e democrático desse sistema político precisam ser estudados. Compete ao professor, com base em sua formação e em seu entendimento sobre os autores da tradição da filosofia política, escolher aqueles que melhor possam expressar as bases filosóficas do liberalismo e da democracia.

A principal habilidade a ser exercitada nesse primeiro movimento genealógico é a leitura filosófica, tanto dos registros culturais provenientes de outras linguagens e meios de difusão, quanto de textos propriamente filosóficos.

O segundo movimento, da autossuperação de si, visa, por um lado, a problematizar esses fundamentos da democracia moderna, de modo a ampliar a capacidade questionadora dos estudantes, e, por outro lado, abrir a possibilidade de pensar diferentemente, de pensar pessoal e criativamente possíveis respostas às questões levantadas, de modo a exercitar a capacidade de pensamento autônomo por parte dos estudantes.

Assim, o primeiro passo desse segundo movimento é prover subsídios à crítica aos fundamentos da democracia liberal por meio da leitura de autores da filosofia política que a contestam (a exemplo do marxismo ou do anarquismo) ou pelo menos que levantem sérias questões (a exemplo de Alasdair MacIntyre e Charles Taylor) sobre os fundamentos do modelo democrático liberal. É importante que esse primeiro passo do segundo movimento seja finalizado com a elaboração de perguntas problematizadoras por parte dos estudantes. Essas perguntas têm em vista preparar o segundo passo metodológico, que se constitui na elaboração de um texto dissertativo pelos estudantes a partir da pergunta elaborada por cada um, assim como do olhar retrospectivo que cada estudante pode fazer em relação às suas primeiras opiniões ou impressões que possuía ao início do estudo do tema. Daí a importância dos registros iniciais, que serão retomados à luz da trajetória de estudo e das inquietações produzidas nesse percurso, de modo a propiciar a cada estudante uma relação criativa com sua própria cultura e, também, consigo mesmo. 
Nesse segundo movimento, a principal habilidade a ser exercitada é a escrita de dissertação filosófica, por meio das fontes textuais utilizadas durante o estudo tendo em vista responder à pergunta selecionada.

Vale ressaltar que os quatro passos metodológicos apresentados não constituem modelo fixo para a elaboração da metodologia com base nos dois movimentos discutidos, mas uma possibilidade, dentre outras. Outro aspecto importante a se destacar é que nem todos os conteúdos filosóficos possam ser tratados por meio da metodologia proposta, necessitando de ajustes e adaptações em razão da peculiaridade da temática estudada.

\section{Considerações finais}

Entende-se que a crítica nietzschiana aos estabelecimentos de ensino de sua época e os apontamentos de sua filosofia tornam-se importantes para se pensar sobre uma metodologia filosófica para o ensino de filosofia no nível médio na atualidade.

Nesse sentido, os apontamentos propostos sobre o pensamento de Nietzsche quanto aos dois movimentos necessários à prática filosófica - o "tornar-se o que se é” como genealogia de si e o além-homem (über-mensch) como autossuperação -, podem contribuir para o estabelecimento de uma metodologia de ensino que parta dos valores constitutivos do que se é em direção ao vir a ser próprio de cada sujeito envolvido com o filosofar na escola, à medida que esses movimentos possam ser tomados como referência para constituição de uma prática filosófica de ensino de filosofia que considere autonomia, cultura e transformação no processo educacional, de acordo com a perspectiva nietzschiana para a educação (ZUBEN; MEDEIROS, 2013).

Assim, é válido destacar que pretende-se, no decorrer da pesquisa, aprofundar as ideias e pensar como esses dois movimentos podem se constituir como práticas de ensino de filosofia, buscando esclarecer que o ensino de filosofia precisa comportar um primeiro movimento de aprendizagem que passe por um diagnóstico da cultura específica dos estudantes, de modo a propiciar-lhes o movimento de um diagnóstico de si mesmos, e também criar as condições para um segundo movimento de afirmação criativa de si, em que a singularidade própria de cada estudante pode se manifestar como aprendizagem para além de si, como superação de si. Desse modo, espera-se que esses dois movimentos sirvam como base para o desenvolvimento e para a construção de uma metodologia de ensino médio de filosofia. 


\section{Referências}

DIAS, Rosa Maria. Nietzsche, vida como obra de arte. Organização Evandro Nascimento. Rio de Janeiro-RJ: Civilização Brasileira, 2011.

FOUCAULT, Michel. Dits et Écrits I - 1954-1969. Paris: Gallimard, 1994.

LARROSA, Jorge. Como se chega ao que se é. Para além da Bildung. In: LARROSA, Jorge (Org.). Nietzsche e a Educação. 3. ed. Tradução Semíramis Gorini da Veiga. Belo Horizonte: Autêntica, 2009, p. 41-67.

LARROSA, Jorge. Ler em direção ao desconhecido. Para além da Hermenêutica. In: LARROSA, Jorge (Org.). Nietzsche e a educação. 3. ed. Tradução Semíramis Gorini da Veiga. Belo Horizonte: Autêntica, 2009, p. 13-40.

NIETZSCHE. Friedrich W. Genealogia da moral: uma polêmica. Tradução e notas de Paulo César de Souza. São Paulo: Companhia das Letras, 1998. 2001.

A gaia ciência. Tradução Paulo César de Souza. São Paulo: Companhia das Letras,

Ecce homo. Madrid: Alianza, 1971.

III Consideração intempestiva: Schopenhauer Educador. In: MELO SOBRINHO, Noéli Correia de (Org.). Escritos sobre educação: Friedrich Nietzsche. São Paulo: Loyola, 2003a. p. 138-222.

Sobre o Futuro dos nossos estabelecimentos de ensino. In: MELO SOBRINHO, Noéli Correia de (Org.). Escritos sobre educação: Friedrich Nietzsche. São Paulo: Loyola, 2003b. p. 41-137.

ZUBEN, Marcos de Camargo Von; MEDEIROS, Rodolfo Rodrigues. Nietzsche e a educação: autonomia, cultura e transformação. Trilhas filosóficas. Revista da Faculdade de Filosofia da UERN, Caicó-RN, ano VI, n. 1, p. 71-93, jan.-jun. 2013. 